\title{
Central motor conduction is abnormal in motor neuron disease
}

\author{
D A INGRAM, M SWASH \\ From The London Hospital, London, UK
}

SUMMARY Conduction in the central motor pathways of the brain and spinal cord was studied in 12 patients with motor neuron disease. Six healthy volunteers served as controls. Transcutaneous electrical stimulation of the cortex, cervical cord, thoracic cord and conus medullaris was used to determine motor latencies to the biceps brachii, thenar eminence and tibialis anterior muscles. Prominent, and often asymmetrical, slowing of central motor conduction was demonstrated in seven of the 12 patients; these findings were most marked in the spinal cord and in most cases correlated with clinical features of corticospinal involvement. In general it was more difficult to excite motor pathways in the central nervous system in the patients with motor neuron disease than in control subjects. Evidence of subclinical involvement of central motor pathways was found in five patients. The central lesion in motor neuron disease may thus contribute more significantly to the clinical deficit than has been realised, since the clinical signs of the upper motor neuron lesion are often masked by the more obvious lower motor neuron features.

In motor neuron disease there is degeneration of anterior horn cells, and thus of the lower motor neuron, causing weakness, wasting and fasciculation of somatic muscles. In most cases this is associated with signs of involvement of central motor pathways, causing hyperreflexia, spasticity and extensor plantar responses. At necropsy degeneration and loss of fibres in the corticospinal pathways in the brain and spinal cord is found, which is particularly marked in the caudal parts of these descending pathways. ${ }^{12}$ The combination of muscle wasting with degeneration of the corticospinal tracts led $\mathrm{Charcot}^{3}$ to use the term amyotrophic lateral sclerosis to describe the disease.

Hitherto the extent of corticospinal involvement during life has been assessed by clinical findings, but these are imprecise measures in a disease in which muscular weakness and wasting may be the dominant features. The development of a technique for transcutaneous electrical stimulation of central motor pathways $^{4-6}$ has enabled the fastest conducting motor fibres to be assessed by a simple direct method which uses motor latencies derived from cortical and neck stimulation. ${ }^{56}$ In addition, stimulation at the neck and lower spinal levels enables the fastest motor

Address for reprint requests: Dr M Swash, The London Hospital, London E1 1BB, UK.

Received 29 November 1985 and in revised form 11 April 1986. Accepted 17 April 1986 conduction velocity in the spinal cord to be calculated. This measure is thought to represent conduction in large diameter fibres in the corticospinal tracts ${ }^{7810}$ and might therefore be reduced in degenerative conditions, such as motor neuron disease, in which preferential loss of large diameter myelinated fibres occurs. ${ }^{12}$ We have therefore used these new methods to investigate conduction in the central motor pathways in a group of patients with motor neuron disease of varying severity. The electrophysiological findings are compared with the clinical features of upper motor neuron disturbance.

\section{Patients and methods}

\section{Patients}

Twelve patients, 10 of whom were men, aged between 38 and 75 (mean 57) years with motor neuron disease were studied (table 1). In each of these patients the typical clinical features of the disease were present. ${ }^{9}$ Symptoms had been present for 4 to 48 (mean 15) months. Four patients showed features of bulbar involvement. All had muscular weakness and wasting of varying degree, with fasciculation at rest in several separate myotomes in two or more limbs. Definite clinical signs of corticospinal tract involvement were present in six patients (table 1). The patients were studied shortly after the diagnosis had been established by clinical examination and by investigation in hospital, including EMG, muscle biopsy, CSF and radiological tests as clinically indicated. All patients gave their informed consent to the investigation, which was approved by the Ethical Committee of the London Hospital. 
Table 1 Clinical features of subjects with motor neuron disease

\begin{tabular}{|c|c|c|c|c|c|c|c|c|c|c|c|c|c|c|c|}
\hline Subject & $\begin{array}{l}\text { Age } \\
(y r)\end{array}$ & Sex & $\begin{array}{l}\text { Height } \\
(\mathrm{cm})\end{array}$ & $\begin{array}{l}\text { Duration } \\
\text { (months) }\end{array}$ & $\begin{array}{l}\text { Bulbar } \\
\text { signs }\end{array}$ & $\begin{array}{l}\text { Streng } \\
\text { UL } \\
\text { Prox } \\
R / L\end{array}$ & $\begin{array}{l}\text { h }(M) \\
\text { Dist } \\
R / L\end{array}$ & $\begin{array}{l}\text { C) } \\
L L \\
\text { Prox } \\
R / L\end{array}$ & $\begin{array}{l}\text { Dist } \\
R / L\end{array}$ & $\begin{array}{l}\text { Increc } \\
(L L) \\
R\end{array}$ & $\begin{array}{l}\text { ed tone } \\
L\end{array}$ & $\begin{array}{l}\text { Refle } \\
(L L \\
R\end{array}$ & es & & $\begin{array}{r}r \\
\text { ses } \\
L\end{array}$ \\
\hline $\begin{array}{r}1 \\
2 \\
3 \\
4 \\
5 \\
6 \\
7 \\
8 \\
9 \\
10 \\
11 \\
12\end{array}$ & $\begin{array}{l}72 \\
57 \\
41 \\
60 \\
71 \\
38 \\
55 \\
56 \\
52 \\
75 \\
63 \\
50\end{array}$ & $\begin{array}{l}\mathbf{M} \\
\mathbf{F} \\
\mathbf{M} \\
\mathbf{F} \\
\mathbf{M} \\
\mathbf{M} \\
\mathbf{M} \\
\mathbf{M} \\
\mathbf{M} \\
\mathbf{M} \\
\mathbf{M} \\
\mathbf{M}\end{array}$ & $\begin{array}{l}180 \\
157 \\
175 \\
157 \\
173 \\
165 \\
170 \\
183 \\
185 \\
178 \\
178 \\
180\end{array}$ & $\begin{array}{r}4 \\
4 \\
6 \\
6 \\
7 \\
9 \\
10 \\
14 \\
17 \\
26 \\
30 \\
48\end{array}$ & $\begin{array}{l}\text { Present } \\
\text { Present } \\
\text { Present } \\
\text { Present }\end{array}$ & $\begin{array}{l}4 / 4 \\
4 / 5 \\
4 / 4 \\
5 / 5 \\
5 / 5 \\
4 / 4 \\
5 / 4 \\
4 / 4 \\
5 / 4 \\
5 / 5 \\
2 / 3 \\
4 / 4\end{array}$ & $\begin{array}{l}3 / 4 \\
4 / 4 \\
1 / 3 \\
1 / 2 \\
5 / 4 \\
1 / 4 \\
5 / 3 \\
5 / 5 \\
5 / 4 \\
5 / 5 \\
3 / 3 \\
4 / 4\end{array}$ & $\begin{array}{l}4 / 5 \\
3 / 5 \\
3 / 5 \\
1 / 4 \\
4 / 4 \\
4 / 4 \\
5 / 4 \\
5 / 5 \\
5 / 5 \\
5 / 4 \\
3 / 3 \\
4 / 4\end{array}$ & $\begin{array}{l}5 / 5 \\
4 / 5 \\
5 / 5 \\
2 / 2 \\
5 / 0 \\
4 / 4 \\
5 / 4 \\
5 / 5 \\
5 / 5 \\
5 / 1 \\
2 / 2 \\
4 / 4\end{array}$ & $\begin{array}{l}+ \\
+ \\
+ \\
+\end{array}$ & $\begin{array}{l}+ \\
+ \\
+ \\
+ \\
+ \\
+\end{array}$ & $\begin{array}{l}3 \\
4 \\
3 \\
2 \\
1 \\
3 \\
2 \\
2 \\
2 \\
2 \\
2 \\
3\end{array}$ & $\begin{array}{l}3 \\
4 \\
3 \\
2 \\
1 \\
3 \\
2 \\
2 \\
2 \\
2 \\
2 \\
3\end{array}$ & $\begin{array}{l}\uparrow \\
\uparrow \\
0 \\
\downarrow\end{array}$ & $\begin{array}{l}1 \\
1 \\
1 \\
1\end{array}$ \\
\hline
\end{tabular}

UL = upper limb, $L L=$ lower limb; $R=$ right, $L=$ left; Prox = proximal, Dist = distal

Strength = MRC grading

Reflexes = Grading 0 absent, 1 present, 2 brisk, 3 very brisk, 4 very brisk with clonus

Plantar responses $=$ Grading $\downarrow$ flexor, $\uparrow$ extensor, $O$ unobtainable

Cortical stimulation

Transcutaneous stimulation of the motor cortex was achieved using a Digitimer D180 stimulator developed from that designed by Merton and Morton. ${ }^{4}$ Saline-soaked pad electrodes, each of $1 \mathrm{~cm}$ diameter and mounted in a Perspex
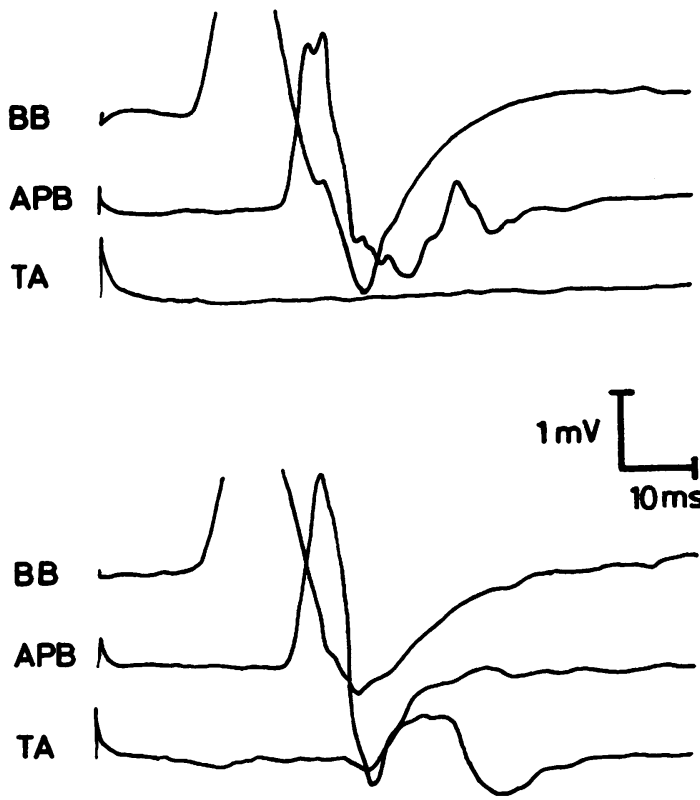

Fig 1 Motor responses from the contralateral biceps brachii $(B B)$, thenar eminence $(A P B)$ and tibialis anterior (TA) recorded simultaneously after two consecutive capacitor stimuli to motor cortex (upper and lower groups of traces). Not the reproducible maximal potentials from $B B$ and $A P B$. The effect of weak background facilitation at the time of the second stimulus is shown for TA in the lower group. holder $5 \mathrm{~cm}$ apart, were held in contact with the scalp, after carefully cleaning the site chosen for stimulation with saline. The patient lay semi-recumbent on a couch. The anode was placed over the convexity of the skull midway between the surface markings of the motor cortex for leg and arm areas
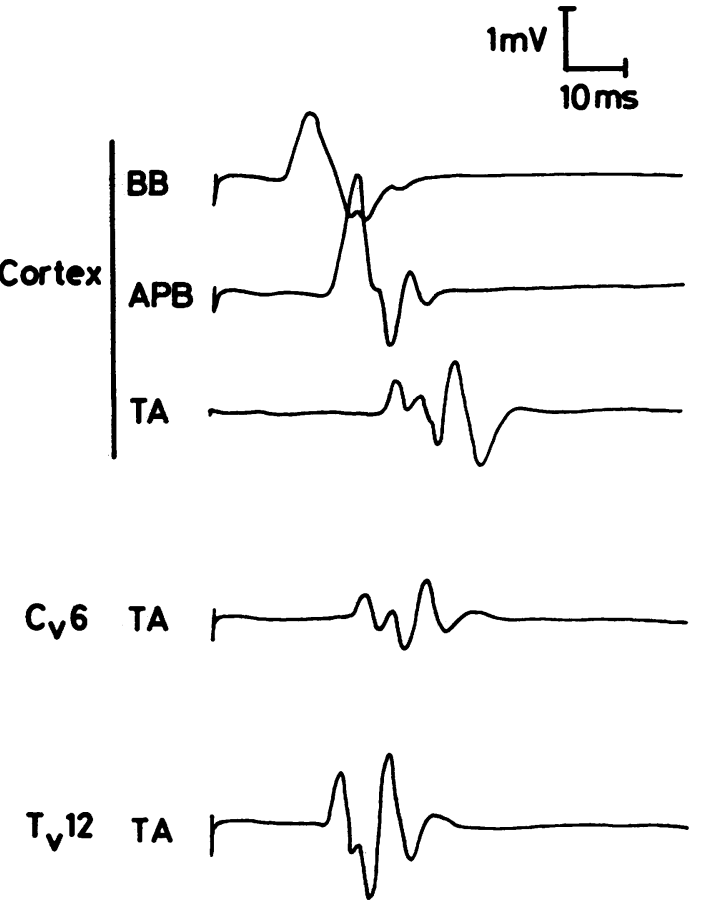

Fig 2 Motor responses to supramaximal stimulation at cortex, Cv6 and Tv12 in a patient with low normal spinal conduction velocity. The waveforms recorded from $T A$ have similar morphology following stimulation at each site which permits reliable estimates of fastest conducting fibres to be made. 


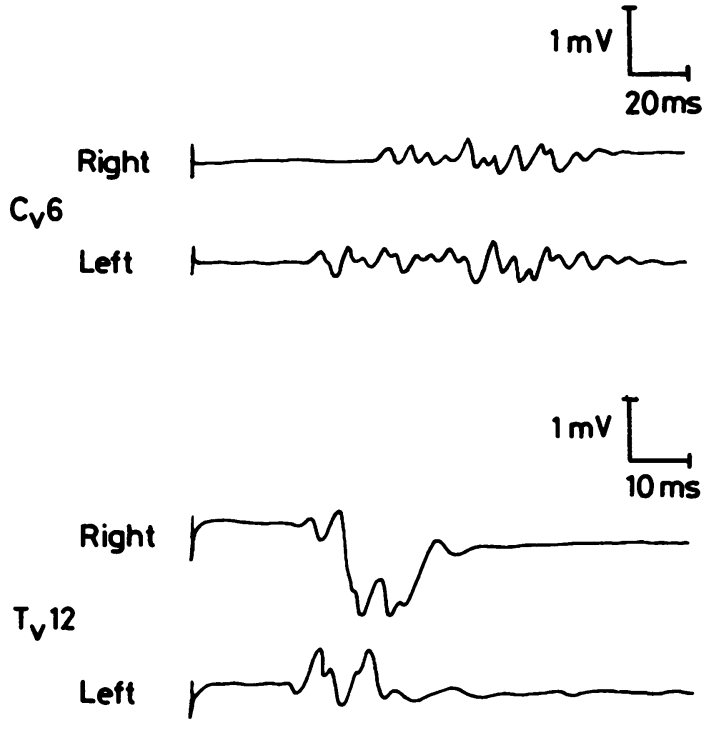

Fig 3 Simultaneous recordings from right and left $T A$ in case 1 after supramaximal stimulation at Cv6 and Tv12. Very delayed and dispersed responses of low amplitude were elicited by C 16 stimulation which contrasted with the relatively well-formed potentials evoked by the low thoracic stimulus. Note the different timebases.

$(6 \mathrm{~cm}$ inferior to the vertex and $1 \mathrm{~cm}$ posterior to a line drawn between the vertex and the tragus). The cathode was placed anterior to the anode; slight adjustments were occasionally required to obtain the optimal position. Saline-soaked earth strap electrodes were applied to all four limbs between the stimulating and recording electrode sites. Single capacitor discharges of 200 to 1000 volts, decaying with a time constant of 50 to $100 \mu \mathrm{s}$, were applied to the right and left motor cortex in sequence. In order to obtain a maximal response the patient was asked to tense slightly the muscle from which the response was to be recorded. ${ }^{510}$ Provided that the stimulus used was adequate to excite maximally the muscle at rest, this manoeuvre had no effect on the latency of the response but the associated increase in amplitude ${ }^{56}$ improved identification of the earliest components of the waveform. The evoked muscle responses were recorded using standard EMG amplifiers, mounted in a Medelec MS6 EMG apparatus, with a bandpass of $8 \mathrm{~Hz}$ to $3.2 \mathrm{kHz}$. Motor responses (figs 1 and 2 ) were recorded with surface electrodes placed over biceps brachii, thenar eminence and tibialis anterior muscles bilaterally and the latencies were measured from paper print-outs. In each patient at least three recordings were made from each muscle for each stimulation site in order to ensure the consistency of the motor latency.

\section{Spinal stimulation}

Spinal motor conduction was assessed using the method we have described previously. ${ }^{78}$ The same stimulating device used for cortical stimulation was employed to deliver single capacitor discharges of 200 to 1000 volts, decaying with a time constant of 50 to $100 \mu$ s via saline-soaked pad electrodes mounted $5 \mathrm{~cm}$ apart in a Perspex holder. The stimulating cathode was applied firmly to the skin in the midline between the $\mathrm{C} 6$ and $\mathrm{C} 7$, and between the $\mathrm{T} 12$ and $\mathrm{L1}$, vertebral spines in sequence, with the anode directed cranially. The skin was cleansed with saline prior to stimulation. The subject lay in the left lateral position and saline-soaked strap electrodes were applied to all four limbs between the stimulating and recording electrodes. Widespread muscle contraction in both proximal and distal muscle groups caudal to the stimulus was usually observed, and this was perceived by the subject as a jolt. Tensing the muscle at the time of the stimulus did not enhance the evoked muscle response to spinal stimulation. In each case at least three supramaximal shocks, greater than $120 \%$ maximal, were delivered and the muscle responses to stimulation at the two spinal levels were recorded simultaneously from right and left tibialis anterior muscles (figs 2 and 3). These responses were recorded as for cortical stimulation (see above) and latencies measured from paper printouts. If no motor responses could be elicited by stimulation at the neck, the procedure was repeated with the stimulating cathode placed in the midline between the T8 and T9 vertebral spines. Finally, the length of the spine between the cathodal stimulation sites was obtained by surface measurement, which enabled spinal cord motor conduction velocity to be calculated for the spinal segments C6-T12 or T8-T12.

\section{Normal controls}

Control data were obtained for both cortical and spinal stimulation, under identical experimental conditions, recording the responses from the biceps brachii, thenar eminence and tibialis anterior muscles of six healthy volunteers aged between 23 and 53 (mean 40) years. All subjects were members of the hospital staff who gave their informed consent to the investigation. The spinal motor conduction velocity in these subjects was similar to that reported by Snooks and Swash ${ }^{78}$ in 21 normal subjects. It has previously been shown that spinal motor conduction velocity does not vary with age in normal adults. ${ }^{78}$

\section{Peripheral motor conduction}

Conventional methods were used to measure motor conduction velocity in the median and common peroneal nerves, and in other mixed nerves when appropriate. Distal motor latency and amplitude, maximal motor conduction velocity and shortest F-wave latency were routinely measured.

\section{Results}

The electrophysiological results are summarised in tables 2 and 3.

\section{UPPER LIMBS}

Motor latencies obtained from stimulation of motor cortex, and of spinal cord at $\mathrm{C6}$, by recording the motor responses of the biceps brachii and the thenar muscles in the arms are shown in table 2.

\section{Cortical stimulation}

In all patients except cases 6,10 and 12 , stable muscle 
Table 2 Central motor conduction (ms) for upper limb muscles

\begin{tabular}{|c|c|c|c|c|c|c|c|c|c|c|c|c|}
\hline \multirow[b]{2}{*}{ Subject } & \multicolumn{4}{|c|}{ Biceps brachii } & \multicolumn{4}{|c|}{ Thenar eminence } & \multicolumn{4}{|c|}{$C C T$ (cortex-C6) } \\
\hline & $\begin{array}{l}\text { Cortex } \\
R\end{array}$ & $L$ & $\begin{array}{l}C 6 \\
R\end{array}$ & $L$ & $\begin{array}{l}\text { Cortex } \\
R\end{array}$ & $L$ & $\begin{array}{l}C 6 \\
R\end{array}$ & $L$ & $\begin{array}{l}B B \\
R\end{array}$ & $L$ & $\begin{array}{l}\text { Thenar } \\
R\end{array}$ & $L$ \\
\hline \multirow[t]{2}{*}{$\begin{array}{l}1 \\
2 \\
3 \\
4 \\
5 \\
6 \\
7 \\
8 \\
9 \\
10 \\
11 \\
12 \\
\text { Normal } \\
\text { (mean } \pm \text { SD) }\end{array}$} & $\begin{array}{l}\text { ND } \\
11.0 \\
\text { ND } \\
11.3 \\
12.3 \\
12.8 \\
11.8 \\
13.0 \\
\text { ND } \\
\text { ND } \\
-\end{array}$ & $\begin{array}{l}\text { ND } \\
10 \cdot 5 \\
\text { ND } \\
11 \cdot 0 \\
12 \cdot 0 \\
12 \cdot 5 \\
12.0 \\
13 \cdot 3 \\
\text { ND } \\
\overline{N D} \\
-\end{array}$ & $\begin{array}{l}\text { ND } \\
5.8 \\
\text { ND } \\
4.9 \\
7.8 \\
5.0 \\
6.8 \\
6.5 \\
4.8 \\
6.5 \\
\text { ND } \\
5.5\end{array}$ & $\begin{array}{l}\text { ND } \\
5.0 \\
\text { ND } \\
4 \cdot 4 \\
6.0 \\
4.8 \\
6.5 \\
7.0 \\
4.8 \\
4.5 \\
\text { ND } \\
6.0\end{array}$ & $\begin{array}{l}\text { ND } \\
22.0 \\
\text { ND } \\
16 \cdot 8 \\
27 \cdot 0 \\
\overline{22.0} \\
23.0 \\
\text { ND } \\
25 \cdot 0 \\
\text { ND } \\
-\end{array}$ & $\begin{array}{l}\text { ND } \\
20 \cdot 3 \\
\text { ND } \\
17 \cdot 8 \\
27 \cdot 0 \\
21 \cdot 3 \\
25 \cdot 0 \\
24 \cdot 5 \\
\text { ND } \\
25 \cdot 0 \\
\text { ND } \\
-\end{array}$ & $\begin{array}{l}12.5 \\
14.8 \\
\text { ND } \\
11.1 \\
18.3 \\
15.0 \\
14.0 \\
16.0 \\
\text { ND } \\
16.0 \\
\text { ND } \\
14.5\end{array}$ & $\begin{array}{l}14.5 \\
13.0 \\
\text { ND } \\
10 \cdot 3 \\
16.5 \\
12.6 \\
14.8 \\
16.0 \\
\text { ND } \\
14.5 \\
\text { ND } \\
15.5\end{array}$ & $\begin{array}{l}\text { ND } \\
4 \cdot 2 \\
\text { ND } \\
6.4 \\
4.5 \\
7 \cdot 8 \\
5.0 \\
6.5 \\
\text { ND } \\
\frac{N D}{-}\end{array}$ & $\begin{array}{l}\text { ND } \\
5 \cdot 5 \\
\text { ND } \\
6.6 \\
6.0 \\
7.7 \\
5.5 \\
6.3 \\
\text { ND } \\
\frac{\mathrm{ND}}{-}\end{array}$ & $\begin{array}{l}\text { ND } \\
7 \cdot 2 \\
\text { ND } \\
5 \cdot 7 \\
8 \cdot 7 \\
8 \cdot 0 \\
7.0 \\
\text { ND } \\
9.0 \\
\text { ND } \\
-\end{array}$ & $\begin{array}{r}\text { ND } \\
7 \cdot 3 \\
\text { ND } \\
7 \cdot 5 \\
10 \cdot 5 \\
8 \cdot 7 \\
10 \cdot 2 \\
8 \cdot 5 \\
\text { ND } \\
10 \cdot 5 \\
\text { ND } \\
-\end{array}$ \\
\hline & \multicolumn{2}{|c|}{$10.9 \pm 1.4$} & \multicolumn{2}{|c|}{$4.6 \pm 0.6$} & \multicolumn{2}{|c|}{$20 \cdot 3 \pm 2 \cdot 3$} & \multicolumn{2}{|c|}{$12 \cdot 1 \pm 1 \cdot 0$} & \multicolumn{2}{|c|}{$6.2 \pm 1.6$} & \multicolumn{2}{|c|}{$8 \cdot 3 \pm 2 \cdot 0$} \\
\hline
\end{tabular}

CCT $=$ central conduction time

$\mathrm{ND}=$ not done

$-=$ stimulation ineffective at cortex

Table 3 Central motor conduction for lower limb muscles

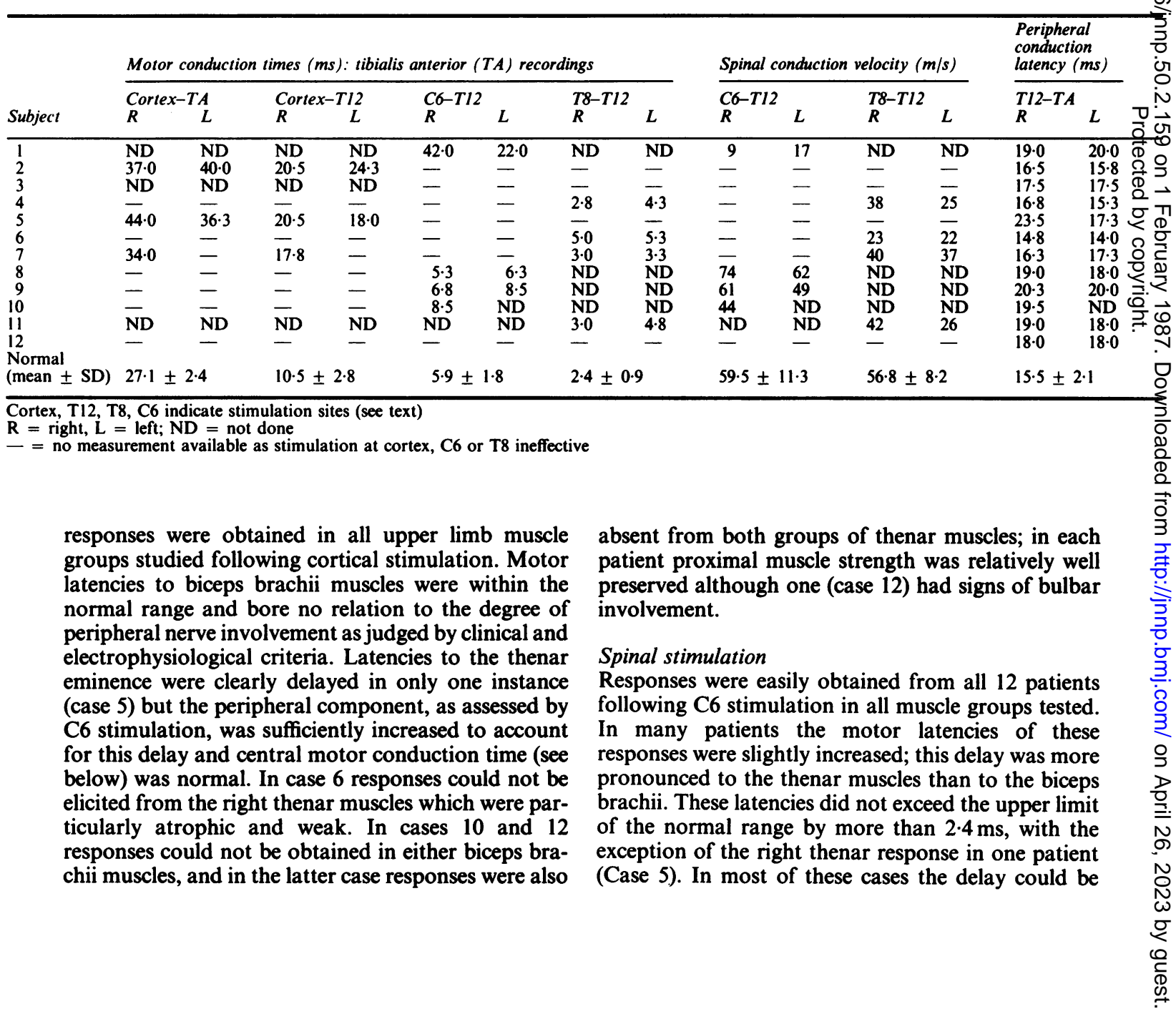


accounted for by a modest increase in the corresponding median nerve distal motor latency and in case 5 this was also reflected in the slightly increased shortest $F$ wave latency $(32 \mathrm{~ms})$. In all instances of increased motor latency after spinal stimulation at $\mathrm{C} 6$ the central motor conduction times (see below) were normal. The amplitudes of the evoked muscle responses after central stimulation were not routinely measured but, where this was done, the amplitudes of the evoked muscle responses to $\mathrm{C} 6$ stimulation were normal, or reduced commensurate with the degree of peripheral nerve involvement. In no case were unusually large potentials encountered.

\section{Central motor conduction time}

This was calculated for the two motor pathways (to biceps brachii and muscles of thenar eminence bilaterally) by subtracting the latency of the response initiated by spinal stimulation at $\mathbf{C} 6$ from that obtained following cortical stimulation (table 2). In all cases central motor conduction time was within normal limits. The mean central conduction time for the motor pathways supplying the biceps brachii and the thenar muscles on both sides were almost identical to the respective values obtained for the control group (table 2). However individual patients (cases 5,7 and 10) showed values for the thenar muscles which were at the upper limit of the normal range and in one (case 7) an abnormal right-left asymmetry was present. In cases 5 and 7 the central conduction times for motor pathways to the biceps brachii muscles were symmetrical and in the lower part of the normal range. This discrepancy between conduction times to biceps brachii and thenar muscles, at least for these two cases, suggests a differential involvement of upper motor neuron pathways supplying proximal and distal muscle groups as is frequently observed clinically and has similarly been demonstrated for the motor neuronal pools innervating these muscles by other electrophysiological methods. ${ }^{17}$

\section{LOWER LIMBS}

Motor responses were recorded in tibialis anterior muscles bilaterally following cortical, C6 and T12 stimulation (table 3). If C6 stimulation was unsuccessful, T8 stimulation was also carried out. Signs of corticospinal involvement were prominent in cases $1,2,3,4,6$ and 12 in whom the plantar responses were extensor, but deep tendon reflexes were abnormally brisk in all patients except case 5. In cases 5, 10 and 11 muscular weakness was severe, precluding objective assessment of reflex activity in relation to normal. However, in these patients the presence of active tendon reflexes was itself probably indicative of upper motor neuron lesions. Similarly, it was not always easy to assess the plantar responses when distal leg muscles were very weak (cases 4 and 11).

\section{Cortical stimulation}

Cortical inexcitability was encountered in six of the twelve patients tested (cases 4, 6, 8, 9, 10 and 12). This refractoriness was not related to age; indeed there were more younger than older patients in this group (table 3). When scalp stimulation was successful the conduction time from cortex to T12 was delayed (cases 2, 5 and 7). This delay was asymmetrical and correlated with the presence of weakness but not with clinical signs of upper motor neuron involvement, suggesting that this part of the investigation had revealed subclinical lesions in these patients.

\section{Spinal stimulation}

Responses following spinal stimulation at T12 were easily obtained in all 12 patients (see table 1). By contrast, stimulation at $\mathrm{C} 6$ was unsuccessful in 7 of the 11 patients in whom this was carried out (cases 2-7 and 12). This finding contrasted with the results obtained in normal subjects in whom spinal stimulation at C6 was invariably successful and resulted in wellformed, stable potentials. In cases $4,6,7$ and 11 , additional stimulation at $\mathrm{T} 8$ elicited stable waveforms which allowed spinal conduction latencies and velocities to be calculated for the lower spinal segment (see below).

In case 10 , normal responses were obtained from the right tibialis anterior but were absent from the left tibialis anterior which was very weak and wasted. The presence of marked weakness and wasting did not necessarily preclude measurements of central motor conduction in other cases. For example, in case 5 no voluntary contraction could be observed or recorded in the right tibialis anterior. Despite this, recordings made from the tibialis anterior muscles during cortical stimulation with attempted voluntary activation revealed bilateral and asymmetrical slowing of central motor conduction (table 3 ). In four patients (cases 2 , 3,5 and 12) spinal stimulation was unsuccessful at both the C6 and T8 sites. Although muscular weakness was not marked, clinical features of corticospinal involvement were prominent in all except case 5 . However, as noted above, conduction time from the cortex to T12 in case 5 was markedly delayed suggesting that central motor pathways were in fact abnormal despite the absence of definite clinical signs.

In case 1 the delayed responses to $\mathrm{C} 6$ stimulation were also prominently dispersed (fig 3 ) and contrasted with the well-formed responses to T12 stimulation. This dispersion could reflect asynchronous firing of anterior horn cells in response to abnormal dispersion of the descending volleys in central motor tracts or to abnormal spread of the excitation times of the ante- 


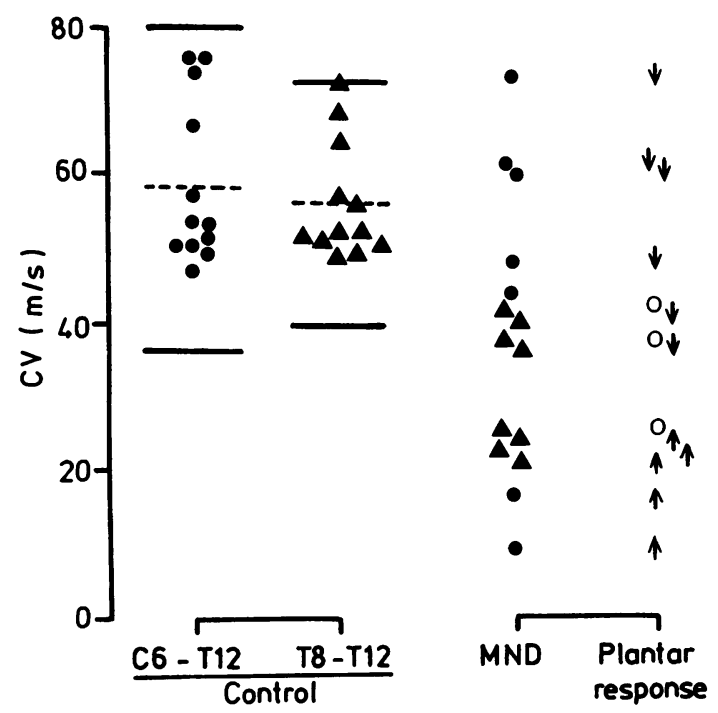

Fig 4 Spinal motor conduction velocities for the normal control group (closed circles C6-T12 segment; closed triangles T8-T12 segment) compared with those obtained from the motor neuron disease patients. In each motor neuron disease case the corresponding plantar response ( $\downarrow$ flexor, $\uparrow$ extensor, $\bigcirc$ unobtainable) is plotted to the right. Note the close relationship between the clinical and electrophysiological findings. Bars: mean $\pm 2 S D$.

rior horn cells. The additional possibility of repetitive firing of lower motor neurons, either individually or in groups, could not be tested in the present investigations. The difference in morphology of the responses obtained in tibialis anterior following stimulation at the two sites suggests that T12 stimulation might have excited lower motor neurons in this case.

\section{Spinal motor conduction velocity}

This was calculated using the spinal conduction time which had been obtained by subtracting the latency of the $T 12$ response in tibialis anterior from the latency of the response to stimulation at $\mathrm{C} 6$ or T8 spinal levels (table 3). In all the patients in whom this could be done, slowing of spinal motor conduction velocity correlated with clinical signs of corticospinal involvement (fig 4). Thus in cases, 1, 4 and 6 spinal motor conduction velocity was slowed and this was associated in each of these three cases with extensor plantar responses. In cases 7, 8, 9 and 10, on the other hand, spinal motor conduction velocity was normal and the plantar responses were flexor. In cases 8 and 9 , the spinal motor conduction velocity, although within the normal range, was markedly asymmetrical (normal right-left difference $3.3 \pm 2.7 \mathrm{~m} / \mathrm{s}$ ), suggesting the presence of subclinical involvement of cor- ticospinal tracts in the spinal cord in these patients. Furthermore, although accurate assessment of the plantar responses could not be made in two patients (cases 4 and 11), spinal motor conduction velocity measurements in case 11 revealed asymmetrical involvement of these motor pathways with clear left sided slowing (table 3 and fig 3 ).

\section{Discussion}

Transcutaneous cortical and spinal stimulation techniques provide an effective and rapid method for the direct assessment of conduction in the central motor pathways of the awake human subject. ${ }^{4-8}$ Slowed conduction in the central motor pathways between the cortex and neck has been demonstrated in patients with multiple sclerosis by Cowan et al. ${ }^{11}$ In the spinal cord slowing of fastest motor conduction velocity between the neck and conus medullaris, thought to represent conduction in the largest diameter corticospinal neurons, ${ }^{7810}$ has been reported in multiple sclerosis and in chronic progressive radiation myelopathy. ${ }^{8}$

The possible experimental errors inherent in the use of these techniques in the study of central motor pathways in humans have been discussed in these earlier reports. In the present study we have calculated the spinal motor conduction velocity using surface measurements without correction for spinal curvature and the values obtained are probably slight overestimations of the true velocities, since surface measurements of spinal length slightly overestimate the length of the spinal cord. ${ }^{812}$ We have used the measure of conduction velocity since it provides a convenient normalisation for conduction distance, although we accept that the specific structures excited in the spinal canal by surface stimulation are not, at present, fully defined.

Our results confirm the observations made by others ${ }^{11}$ that the central conduction time (Cortex-C6) in normal subjects is shorter to biceps brachii than to the thenar muscles. This discrepancy presumably reflects anatomical differences in pathway length. The values we have observed tend to be slightly longer than those measured by previous authors. ${ }^{11}$

The most striking pathological features of the central motor pathway in motor neuron disease is asymmetrical loss of large myelinated motor axons in the corticospinal tracts, occurring in association with degeneration of the motor cells of the motor cortex and of the anterior horn cells of the spinal cord. ${ }^{121314}$ The electrophysiological results in the present study reflect these underlying changes and in most cases correlate with the presence or absence of definite upper motor neuron involvement. Thus reduced spinal motor conduction velocities (cases $1,4,6,11$ ) were associated with extensor plantar responses except in 
case 11 in which plantar responses could not be obtained owing to the prominent distal weakness. The latter case probably illustrates the ability of the stimulation technique to identify subclinical lesions. Further examples are seen in cases 8 and 9 in which spinal conduction velocity was within the normal range but an abnormal asymmetry of spinal motor conduction was present, and in case 5 in which flexor plantar responses were associated with bilateral slowing of motor conduction in central motor pathways. Asymmetrical slowing was a prominent feature of the abnormality of central motor conduction (table 3 and fig 3).

In many of our patients with motor neuron disease it proved difficult to excite the motor pathways in the central nervous system particularly at the cortex and neck (table 2). This contrasts with the findings in control subjects, in whom muscle responses were readily obtained at all stimulation sites, and implies an increased threshold to excitation in these patients. The relative inexcitability of the central motor pathways in motor neuron disease probably reflects the combined effect of motor cell loss, axonal changes and secondary demyelination. These structural changes are also likely to be relevant to the observed slowing of spinal motor conduction. In five patients decreased spinal conduction velocity could be demonstrated but the corresponding central conduction times (from cortex to neck) were normal. If the disease involves a dyingback process ${ }^{1}$ then longer fibre tracts would be expected to show the most prominent conduction abnormalities; this concept is supported by our findings and is in agreement with the histological observations that demyelination and axonal loss predominates in the caudal segments of the spinal cord. ${ }^{2}$

In advanced disease, the selective loss of the larger diameter, fast-conducting fibres would be expected to result in a further reduction of the observed conduction velocity. The velocities of the fast-conducting corticospinal neurons are known in cats to range from 20 to $70 \mathrm{~m} / \mathrm{s}$ and this distribution is probably similar to that in primates. ${ }^{10}$ In most patients with signs of upper motor neuron involvement, therefore, loss of larger fibres could account for the observed slowing of motor conduction velocity in the spinal cord. Slowing of motor conduction would be more marked if the surviving axons were subject to partial, distal demyelination; this combination of features would, for example, explain the prominent slowing in case 1 in which the very delayed and dispersed muscle potentials are similar to those described in patients with multiple sclerosis. ${ }^{7811}$

The observed slowing of calculated spinal motor conduction velocity in motor neuron disease might also be partly due to asynchrony of arrival of corticospinal impulses at anterior horn cells, and so to an increase in the time required to depolarise diseased lower motor neurons. However, this alone is unlikely to explain latency increases of the magnitude we have observed, since central conduction times for the upper limb muscles remain within normal limits even in those patients with evidence of marked peripheral nervous system involvement. It is also feasible that in advanced disease other central motor pathways, including the reticulospinal and rubrospinal tracts might contribute to the fastest conducting fibres; the present technique is not capable of distinguishing these different responses. The capacity of diseased central motor neurons for regeneration is not known but, if this were significant, the resulting fibres would be of smaller calibre with shortened internodes and fewer myelin lamellae. Thus if conduction were maintained, it would be slowed. Histological evidence in support of this suggestion has been provided in morphological studies of the ventral roots ${ }^{1415}$ but there have been no quantitative studies of the fibre diameter distribution in the central motor pathways in motor neuron disease.

The marked abnormalities of central motor conduction we have found in the brain and spinal cord even in the relatively early stages of motor neuron disease, suggest that upper motor neuron disturbances may constitute a more important part of the clinical deficit than has previously been realised. In the later stages of the disease the clinical picture is almost invariably dominated by wasting and fasciculation, and weakness has therefore usually been ascribed largely to these features of lower motor neuron involvement. Indeed, the clinical features of upper motor neuron involvement may be overwhelmed by the lower motor neuron signs (see cases 4 and 11). The significance of the upper motor neuron disorder has therefore been relatively neglected in attempts to formulate a theory of pathogenesis, but may be important in several respects, for example in understanding the impaired capacity for collateral sprouting revealed by electrophysiological ${ }^{16}$ and histological ${ }^{17}$ studies. It may also contribute significantly to the fatigue and poor coordination of muscular activity experienced by patients in whom peripheral conduction is normal and re-innervation is well established. Furthermore, these electrophysiological data suggest that, even in the early stages of the disease, the upper motor neuron lesion is widely distributed throughout the central motor pathways in keeping with the findings of histopathological studies on necropsy material which have shown widespread pallor of myelin in the cervical and upper thoracic regions, the cortical white matter, brainstem and internal capsules, in addition to the prominent caudal loss of large corticospinal fibres. ${ }^{12}{ }^{13}$ The asymmetry of the spinal motor conduction abnormality is consis- 
tent with previous clinical, 9 EMG ${ }^{16}$ and pathological $^{213}$ studies of the disease and remains one of the more mysterious aspects of this condition.

This work was funded, in part, by grants from the National ALS Foundation of America, The Motor Neurone Disease Association (of the UK) and from the London Hospital Special Trustees. We gratefully acknowledge the generosity of these organisations.

\section{References}

1 Greenfield JG. System degenerations of the cerebellum, brain stem and spinal cord. In: Blackwood W, Meyer A, McMenemy WH, Norman RM, eds. Neuropathology. London: Edward Arnold, 1958:529.

2 Brownell B, Oppenheimer DR, Hughes JT. The central nervous system in motor neurone disease. $J$ Neurol Neurosurg Psychiatry 1970;33:338-57.

3 Charcot JM. Lectures on the Diseases of the Nervous System. Second Series. Transl. Sigerson G. London: The New Sydenham Society, 1881:181-92.

4 Merton PA, Morton HB. Stimulation of the cerebral cortex in the intact human subject. Nature 1980;285:227.

5 Merton PA, Morton HB, Hill DK, Marsden CD. Scope of a technique for electrical stimulation of human brain, spinal cord and muscle. Lancet 1982;ii:597-600.

6 Marsden CD, Merton PA, Morton HB. Direct electrical stimulation of corticospinal pathways through the intact scalp in human subjects. In: Desmedt JE, ed. Motor Control Mechanisms in Health and Disease. New York: Raven Press, 1983:387-92.

7 Swash M, Snooks SJ. Motor conduction velocity in the human spinal cord. J Physiol (Lond) 1985;360:50P.

8 Snooks SJ, Swash M. Motor conduction velocity in the human spinal cord; slowed conduction in multiple sclerosis and radiation myelopathy. $J$ Neurol Neurosurg Psychiatry 1985;48:1135-9.

9 Mulder DW. Motor neuron disease. In: Rowland LP, ed. Motor Neuron Diseases. New York: Raven Press, 1984:1525-36.

10 Philips GC, Porter R. Corticospinal Neurones: Their role in movement. London: Academic Press, 1977:21-49.

11 Cowan JMA, Dick JPR, Day BL, Rothwell JC, Thompson PD, Marsden CD. Abnormalities in central motor pathway conduction in multiple sclerosis. Lancet 1984;ii:304-7.

12 Desmedt JE, Cheron G. Spinal and far-field components of human somatosensory evoked potentials to posterior tibial nerve stimulation analysed with oesophageal derivations and non-cephalic reference recordings. Electroencephalogr Clin Neurophysiol 1983;56:635-51.

13 Wohlfart G, Swank RL. Pathology of amyotrophic lateral sclerosis: fiber analysis of the ventral roots and pyramidal tracts of the spinal cord. Arch Neurol Psychiatr 1941;46:783-99.

14 Dyck PJ, Stevens JC, Mulder DW, Espinosa RE. Frequency of nerve fiber degeneration of peripheral motor and sensory neurons in amyotrophic lateral sclerosis. Neurology 1975;25:781-5.

15 Hanyu N, Oguichi K, Yanagisawa, Tsukagoshi H. Degeneration and regeneration of ventral root motor fibres in amyotrophic lateral sclerosis. J Neurol Sci 1982;55:99-115.

16 Schwartz MS, Swash M. Pattern of involvement in the cervical segments in the early stage of motor neuron disease: a single fibre EMG study. Acta Neurol Scand 1982;65:424-31.

17 Gurney ME, Belton AC, Cashman H, Antel JP. Inhibition of terminal axonal sprouting by serum from patients with amyotrophic lateral sclerosis. $N$ Engl $J$ Med 1984;311:933-9. 